\title{
Endocannabinoid Signaling in Autism
}

\author{
Bhismadev Chakrabarti ${ }^{1}$ Antonio Persico ${ }^{2,3}$ - Natalia Battista ${ }^{4}$ - Mauro Maccarrone ${ }^{2,5}$
}

Published online: 28 July 2015

(C) The American Society for Experimental NeuroTherapeutics, Inc. 2015

\begin{abstract}
Autism spectrum disorder (ASD) is a complex behavioral condition with onset during early childhood and a lifelong course in the vast majority of cases. To date, no behavioral, genetic, brain imaging, or electrophysiological test can specifically validate a clinical diagnosis of ASD. However, these medical procedures are often implemented in order to screen for syndromic forms of the disorder (i.e., autism comorbid with known medical conditions). In the last 25 years a good deal of information has been accumulated on the main components of the "endocannabinoid (eCB) system", a rather complex ensemble of lipid signals ("endocannabinoids"), their target receptors, purported transporters, and metabolic enzymes. It has been clearly documented that eCB signaling plays a key role in many human health and disease conditions of the central nervous system, thus opening the avenue to the
\end{abstract}

B. Chakrabarti, A. Persico and N. Battista are equal first authors.

Mauro Maccarrone

m.maccarrone@unicampus.it

1 Centre for Integrative Neuroscience and Neurodynamics, School of Psychology and Clinical Language Sciences, University of Reading, Reading, UK

2 Center of Integrated Research and School of Medicine, Campus Bio-Medico University of Rome, Via Alvaro del Portillo 21, 00128 Rome, Italy

3 Mafalda Luce Center for Pervasive Developmental Disorders, Milan, Italy

4 Faculty of Bioscience and Technology for Food, Agriculture and Environment, University of Teramo, Teramo, Italy

5 European Center for Brain Research (CERC)/Santa Lucia Foundation, Rome, Italy therapeutic exploitation of eCB-oriented drugs for the treatment of psychiatric, neurodegenerative, and neuroinflammatory disorders. Here we present a modern view of the eCB system, and alterations of its main components in human patients and animal models relevant to ASD. This review will thus provide a critical perspective necessary to explore the potential exploitation of distinct elements of $\mathrm{eCB}$ system as targets of innovative therapeutics against ASD.

Key Words Autism spectrum disorder · endocannabinoid system · fragile $\mathrm{X}$ syndrome $\cdot$ metabolic regulation $\cdot$ reward system

\section{The Endocannabinoid System}

Twenty-five years after the cloning and expression of a complementary DNA that encoded a $G$ protein-coupled receptor, named type-1 cannabinoid $\left(\mathrm{CB}_{1}\right)$ receptor [1], there is a good deal of information on the main components of the so-called "endocannabinoid (eCB) system", as well as on its role in controlling cannabinergic signaling in human health and disease [2-4]. Anandamide (AEA) and 2-arachidonoylglycerol (2-AG) are the most active eCBs as yet identified, although this family of bioactive lipids includes other arachidonic acid (AA) derivatives with cannabimimetic properties (i.e., noladin ether, virodhamine, $N$-arachidonoyldopamine, to name but a few). The classical dogma that eCBs are synthesized and released "on demand" upon (patho)physiological stimuli has been recently revisited on the basis of unexpected evidence for intracellular reservoirs and transporters of eCBs. These new entities have been shown to drive intracellular trafficking of eCBs, adding a new dimension to the regulation of their biological activity [5]. To date, several metabolic routes have 
been described for AEA biosynthesis [6, 7], yet the most relevant pathway is believed to begin with the transfer of AA from the $s n$-1 position of 1,2-sn-di-arachidonoyl-phosphatidylcholine to phosphatidylethanolamine, generating the AEA precursor $N$-arachidonoyl-phosphatidylethanolamine. The latter compound is next cleaved by a specific $N$-acylphosphatidylethanolamine (NAPE)-specific phospholipase $\mathrm{D}$, which has been characterized in detail [8]. However, the degradation of AEA to AA and ethanolamine is mainly due to 2 fatty acid amide hydrolases (FAAH and FAAH-2) $[9,10]$. When FAAH and FAAH- 2 are inhibited, $N$-acylethanolaminehydrolyzing acid amidase cleaves AEA in an alternate route $[11,12]$. The main enzymes responsible for AEA metabolism are reported in Fig. 1.

Much like AEA, the biological activity of 2-AG is controlled through cellular mechanisms that include: 1) synthesis through rapid hydrolysis of inositol phospholipids by a specific phospholipase $\mathrm{C}$ to generate diacylglycerol that is then converted into 2-AG by a sn-1-specific diacylglycerol lipase (DAGL) [13]; and 2) degradation to AA and glycerol by a monoacylglycerol lipase (MAGL) [14], as schematically represented in Fig. 1. AEA and 2-AG can be also oxidized by cyclooxygenase-2, different lipoxygenase isozymes, as well as by cytochrome P450, to generate, respectively, prostaglandin-ethanolamides [15] and prostaglandin-glyceryl esters [16], hydroxy-anandamides and hydroxyleicosatetraenoylglycerols [17], and epoxy-eicosatrienoyl-glycerols [18].

An open question concerning eCB metabolism remains the transport of these compounds across the plasma membrane $[19,20]$. As yet, the most accepted mechanisms are: 1) passive diffusion, which can be favored by the formation of AEAcholesterol complexes, possibly in preferred microdomains called "lipid rafts" [21, 22]; 2) facilitated transport through a purported eCB membrane transporter [23]; and 3) endocytosis assisted by caveolins (reviewed in [24]). Once taken up, intracellular AEA reaches distinct sites, where distinct metabolic and signaling pathways take place. Heat shock protein 70 , and albumin and fatty acid binding proteins 5 and 7 have been shown to act as eCB intracellular transporters, able to ferry AEA (and likely also 2-AG) within the cytoplasm to the nucleus and other destinations, including storage compartments like adiposomes [5, 25].

eCBs act principally through type- 1 and type- $2\left(\mathrm{CB}_{1}\right.$ and $\mathrm{CB}_{2}$ ) cannabinoid receptors. Interestingly, $\mathrm{CB}_{1}$ but not $\mathrm{CB}_{2}$ resides within lipid rafts, and their interaction with these specialized microdomains influences signal transduction thereof [26]. Additionally, eCBs are also able to interact with non$\mathrm{CB}_{1}$ /non- $\mathrm{CB}_{2}$ targets, such as 1) the transient receptor potential vanilloid type 1 channel, which is activated by both AEA and $2-\mathrm{AG}[27,28] ; 2)$ peroxisome proliferator-activated receptor- $\alpha$ and peroxisome proliferator-activated receptor- $\gamma$ [29]; and 3) the orphan G protein-coupled receptor GPR55 $[30,31]$. By interacting with these receptors, eCBs trigger a multiplicity of signaling pathways that are involved in both physiological and pathological conditions [32]. On a final note, the existence of compounds structurally related to eCBs, and collectively known as "eCB-like" substances, should be recalled because of their "entourage effect". These compounds potentiate $\mathrm{eCB}$ activity at their receptors by increasing binding affinity or by inhibiting eCB hydrolysis [33-35]. A schematic representation of eCBs, their molecular targets, biosynthetic and hydrolizing enzymes, and extra- and intracellular transporters, is depicted in Fig. 1.

\section{Autism Spectrum Disorder: Clinical Traits, Neuropsychological Deficits, and Neuroanatomical Underpinnings}

Autism spectrum disorder (ASD) is a complex behavioral condition with onset during early childhood and a lifelong course in the vast majority of cases. It is characterized by deficits in communication and social interaction, as well as by stereotypic behaviors, restricted patterns of interest, and abnormal sensory issues [36]. The diagnosis is based on clinical observation, substantiated by standardized testing of the patient with the Autism Diagnostic Observation ScheduleGeneric [37], later revised into the Autism Diagnostic Observation Schedule-2 [38], and/or by parental interview with the Autism Diagnostic Interview-Revised [39]. To date, no behavioral, genetic, brain imaging, or electrophysiological test can specifically validate a clinical diagnosis of ASD, although these medical procedures are regularly implemented in order to screen for syndromic forms of the disorder (i.e., autism due to known medical conditions). Two essential features distinguish ASD from most other behavioral disorders: 1) an impressive clinical and pathogenetic heterogeneity, which has led to the designaton, by the term "autisms", of a set of neurodevelopmental disorders with early onset in life, sharing autism as a common feature, but produced through distinct processes [40]; 2) the distribution of autistic features as a dimensional continuum in the general population, which fully justifies referring to the "autism spectrum" rather than to a categorical distinction between "affected" and "unaffected" $[41,42]$. As many as 1 in 68 (1.6\%) 8-year-old children receive an ASD diagnosis [43], with a male:female ratio of 4:1. Siblings of children already diagnosed with ASD have a significantly higher incidence of the same disorder, reported at $18.7 \%$ in a prospective follow-up study [44], and ranging from $15 \%$ to $25 \%$ depending on sex and clinical severity. The prospective follow-up of these siblings later diagnosed with ASD has led to the observation that some behavioral abnormalities can appear very early on (e.g.,, sensory issues [e.g., extreme responses to certain sounds/textures, fascination with lights/spinning objects] are already present at 7 months of age), others emerge at 12-14 months (e.g., disengagement 


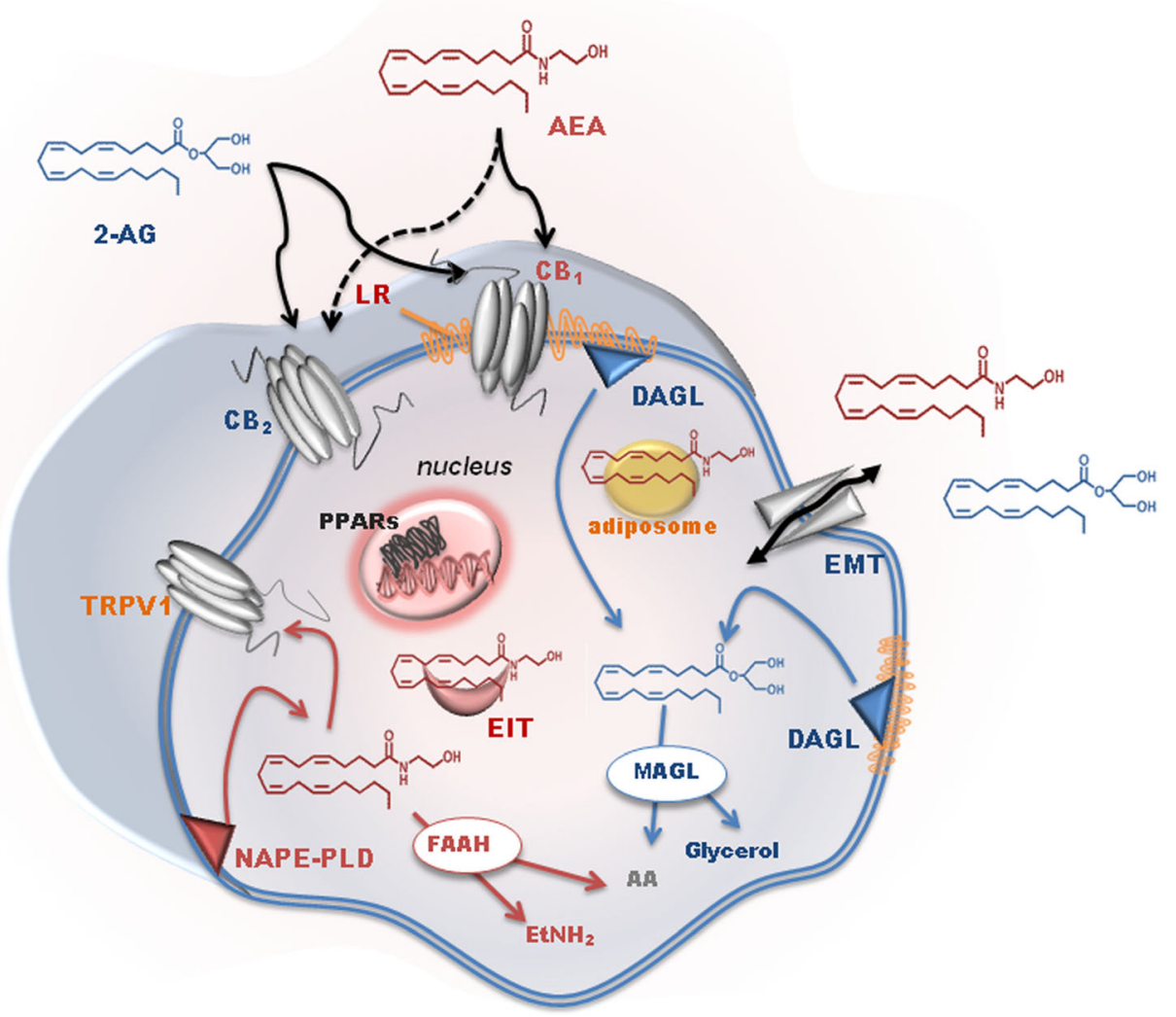

Fig. 1 Schematic representation of the main elements of the endocannabinoid (eCB) system. $N$-arachidonoylethanolamine (AEA) is mainly synthesized by the sequential activity of $N$-acyltransferase (not shown) and $N$-acylphosphatidyl-ethanolamine (NAPE)-specific phospholipase D (NAPE-PLD). The intracellular degradation of AEA is due to a fatty acid amide hydrolase (FAAH) that generates ethanolamine $\left(\mathrm{EtNH}_{2}\right)$ and arachidonic acid (AA). 2-Arachidonoylglycerol (2-AG) is released from membrane lipids through the activity of diacylglycerol lipase (DAGL), and can be hydrolyzed by a cytosolic monoacylglycerol lipase (MAGL), which releases glycerol and AA. Cyclooxygenase-2, lipoxygenase isozymes and cytochrome P450 were omitted for the sake of clarity. Extracellular eCBs can cross the plasma membrane through a

of visual attention), while the bulk of more typical autistic abnormalities has an onset between 14 and 24 months [45-48]. Frequently, comorbid conditions include intellectual disability (65\%), seizures (30\%), and different forms of sleep problems [49-51]; less recognized, but equally impairing, are frequent psychiatric comorbidities, that include anxiety disorders, obsessive-compulsive disorders, and depression [52]. Altered neurodevelopment during early pregnancy represents the neuropathological cause of ASD [53, 54]. Postmortem studies have unveiled neuroanatomical and cytoarchitectonic abnormalities in the cerebellum, inferior olivary complex, deep cerebellar nuclei, hippocampus, amygdala, entorhinal cortex, fusiform gyrus, and anterior and posterior cingulate cortex, with thinner cortical minicolumns, excessive growth of the frontal lobes, and excessive dendritic spine density [55]. These abnormalities are suggestive of derangements occurring purported eCB membrane transporter (EMT), and then they are trafficked within the cytoplasm through eCB intracellular transporters (EIT), which deliver them to their different targets or, alternatively, to storage organelles like adiposomes. Both AEA and 2-AG trigger several signal transduction pathways by acting at type- 1 and type- 2 cannabinoid receptors $\left(\mathrm{CB}_{1}\right.$ and $\mathrm{CB}_{2}$, respectively), or at other non- $\mathrm{CB}_{1} /$ non- $\mathrm{CB}_{2}$ targets, such as peroxisome proliferator-activated receptors (PPARs) in the nucleus. $\mathrm{CB}_{1}$, but not $\mathrm{CB}_{2}$, resides within specialized membrane microdomains enriched in cholesterol and sphingolipids, which are called lipid rafts (LR). AEA (and also 2-AG) can also translocate to the inner membrane leaflet, where it binds to transient receptor potential vanilloid type 1 (TRPV1) channels

during the first/second trimester of pregnancy, namely reduced programmed cell death and/or increased cell proliferation, altered cell migration, abnormal cell differentiation with reduced neuronal body size, abnormal neurite sprouting, and pruning that result in atypical cell-cell wiring. In addition, neurodevelopmental mechanisms extending into late prenatal/postnatal life include reduced synapse formation and delayed myelination [40, 56, 57]. The latter result in abnormal neuronal wiring, which was previously believed to be characterized by long-range hypoconnectivity and local hyperconnectivity [58], but more recently has been shown to be a highly individualized mix of hyper- and hypoconnectivity specific to each single patient with ASD [59]. These abnormalities have been associated with deficits in multiple behavioral tasks that relate to social behavior, such as empathy, theory of mind, joint attention, and face and emotion 
processing. Many of these observed behavioral features suggest a deficit in the social reward processing system in ASD, as we discuss in the following section. The neurocognitive phenotype in ASD stems from a complex and highly heterogeneous array of genetic and environmental causes, with patients ranging from "purely genetic" cases due to known ASD-causing chromosomal aberrations or mutations to "purely environmental" cases due to rare prenatal exposure to specific viral agents, drugs, and toxins [60-62]. In between these extremes, ASD for most cases fully qualifies for the definition of a "complex" disorder, whereby a host of rare and common genetic variants, often but not necessarily in conjunction with epigenetic factors [63], yield the neurodevelopmental abnormalities summarized above, resulting in autistic behaviors. Finally, neuroinflammation is also a frequent finding in postmortem brains of autistic individuals $[64,65]$. It may represent a nonspecific consequence of insufficient neurite pruning and abnormal wiring of neural networks, resulting in elevated oxidative stress (possibly a common feature shared by several neurodevelopmental disorders) [66], but it could also stem from a broader immune dysfunction which, together with gastrointestinal disturbances and recurrent infections, collectively qualifies ASD as a systemic disorder [67-71].

\section{Autism and Reward System}

A deficit in theory of mind and empathy has commonly been suggested to underlie atypical social behavior in individuals with ASD [72]. A set of recent studies raises the possibility that some of these social behavioral deficits in ASD arise due to deficits in reward system functioning [73-75]. This hypothesis is supported by studies that report a lack of social motivation in children with autism [76, 77]. One rationale for the social motivation-based account of ASD relies on the following premise: if individuals with ASD do not find social stimuli rewarding, and hence do not attend to them as much as neurotypicals, then they are less likely to exhibit empathy toward them. An alternative formulation of the social motivation hypothesis suggests that the attention of individuals with and without ASD is drawn to social stimuli to a comparable extent, but individuals with ASD find social stimuli less rewarding, which leads to the observed deficits in empathy (Fig. 2).

Both of these possible accounts of the social motivation hypothesis are faced with a key question. Do people with ASD find social stimuli rewarding or do they have a domain-general dysfunction of the reward system? To test these possibilities, a number of studies have compared processing of social and nonsocial reward stimuli in people with and without ASD. An early study using a continuous performance task found no behavioral evidence for group differences in trials with monetary rewards versus nonrewards
[78]. Similarly, comparable behavioral performance in a reward-processing task using a variant of the go-no-go task was found in children and adults with and without ASD [79, 80]. In contrast, using a similar task, DeMurie et al. [81] demonstrated that children with ASD were slower in responding to social rewards than monetary rewards, but this was not specific to ASD. Overall, the behavioral evidence summarized above appears equivocal about any circumscribed deficit in social reward processing in ASD. Yet, a main group effect in the majority of these studies points toward a domain-general deficit in the reward system. In contrast to the behavioral studies using button-press responses, eyegaze tracking, electroencephalography, and functional magnetic resonance imaging studies suggest clear differences in processing of social rewards in ASD compared with typically developed controls [82]. Eyegaze tracking studies typically involve measuring gaze fixation patterns in response to social and nonsocial stimuli. Children and adults with ASD are found to look less at social stimuli than at nonsocial stimuli [83-85]. Gaze fixation patterns have often been used as proxy metrics related to reward processing [86], thus supporting the hypothesis of atypical processing of social rewards in ASD. Using electroencephalography in children with ASD, a recent study reported lower magnitude of a component related to reward anticipation (stimulus preceding negativity) in response to social versus nonsocial stimuli [87]. Similarly, functional magnetic resonance imaging studies revealed lower activity in the ventral striatum in response to social stimuli (neutral faces) in individuals with ASD [88]. The latter finding is consistent with the observation that a reduced ventral striatal response to happy faces was associated with lower self-reported empathy in individuals with and without ASD [89].

In sum, there is substantial evidence across different techniques to suggest atypical reward processing in ASD. Irrespective of their domain specificity, such functional differences in the reward circuit in ASD have important consequences for the processing of social stimuli. Atypical response to social rewards from an early age can result in deficits in learning about the social world, which, in turn, can lead to social behavioral impairments in adulthood.

\section{Alterations of the eCB System in Autism}

The complexities that make autism hard to understand, from the diagnostic criteria and clinical heterogeneity to the genetic/ environmental causes that provoke communication and behavioral problems to the innovative therapies to be applied in order to give patients the best quality of life, encourage scientists to look at predictive biomarkers and/or therapeutic targets for the pharmacological management of this disorder $[90,91]$. It is now clear that eCB system is altered in several neurodegenerative diseases and, very interestingly, that 


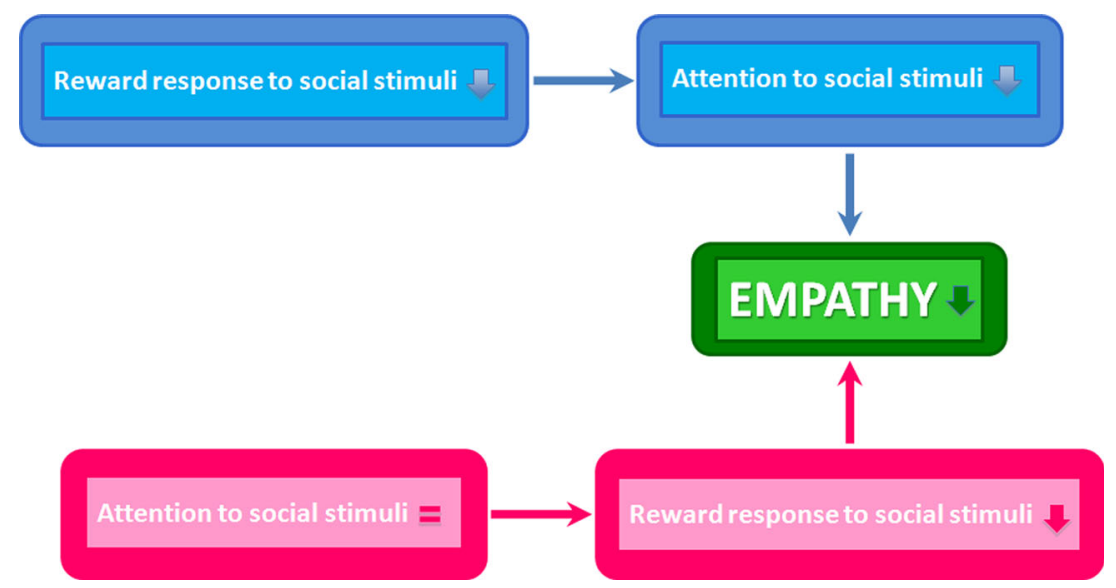

Fig. 2 Two possible routes through which atypical reward processing can lead to reduced empathy as seen in ASD. (Top panel) The first of these routes suggest that a lower reward response to social stimuli reduces the salience of social stimuli and hence how much attention they capture.
The reduced empathy is therefore a product of this reduced attention to social stimuli. (Bottom panel) A second possible route suggests comparable salience for social and nonsocial stimuli in ASD, but lower value for social stimuli in ASD, leading to reduced empathy distinct elements of the eCB system in peripheral blood mirror these perturbations, providing novel and noninvasive diagnostic tools for several neuroinflammatory diseases [92, 93]. In addition, the eCB system controls emotional responses [94], behavioral reactivity to context [95], and social interaction [96]. Thus, it can be hypothesized that alterations in this endogenous circuitry may contribute to the autistic phenotype. In this and the following sections, we critically discuss the evidence for this proposition from animal and human studies. Recent investigations have addressed the involvement of eCBs in autism, where, unfortunately, the role of these bioactive lipids remains poorly understood. Indeed, autism is uniquely human and there are only a few validated animal models (e.g., fmrl knockout mice, BTBR mice, and valproic acid-treated rats), that display autistic-like features. Fragile X syndrome (FXS) is an inherited disorder caused by mutations in FMR1, which is translated into the fragile $\mathrm{X}$ mental retardation 1 protein, which, in turn, plays a role in the development of synapses [97, 98]. Expansion mutations of FMRI produce autistic features in approximately $40 \%$ of patients with FXS, and thus FXS provides a valuable model for identifying novel biomarkers/targets for autism and for dissecting the underlying neurochemical pathways [99]. In the first study addressing eCB system in FXS, it has been reported that the ablation fmrl gene causes a dysfunctional 2-AG metabolism, with increasing DAGL and MAGL activities in the striatum of $\mathrm{fmrl}^{-/-}$mutants, but unaltered striatal 2-AG levels [100]. According to a more recent study [101], stimulation of 2-AG signaling could be a useful treatment for mitigating FXS symptoms because it is able to normalize synaptic activity through type I metabotropic glutamate activation; additionally, genetic or pharmacological attenuation of $\mathrm{CB}_{1}$-dependent signal transduction and blockade of the mammalian target of rapamycin pathway might provide alternative strategies to treat autistic patients [102].
A link between the eCB system and autism was put forward by Schultz [103], who proposed that acetaminophen, an antipyretic drug that is metabolized to a potent inhibitor of the purported eCB membrane transporter AM404, could trigger autism by activating $\mathrm{CB}$ receptors. In line with this, elevated levels of circulating AEA during pregnancy or in the first postnatal days might interefere with the neurodevelopment of offspring, and might increase the risk of delivering autistic children. Abnormalities in sociability and nociception tests, and alterations of distinct elements of eCB system have been reported in adolescent rats on valproic acid [104]. In particular, mRNA levels of the enzymes responsible for 2-AG metabolism (i.e., DAGL and MAGL), which is disrupted in the FXS model of autism [100], were altered in the cerebellum and hippocampus, whereas endogenous levels of 2-AG in the same regions remained at steady state [104]. Interestingly, the content of AEA, $N$-oleoylethanolamine (OEA), and $N$ palmitoylethanolamine (PEA), all of which are substrates of FAAH, were increased in the hippocampus following exposure to sociability tests, suggesting that a deficit in social play behaviors might be due to reduced AEA levels in critical brain areas [104]. Moreover, the same study documented a downregulation of GPR55 and PPAR gene expression, supporting a role for these receptors in the cognitive mechanisms involved in autism [104]. Preliminary data also addressed $\mathrm{CB}_{2}$ as a potential target for autism. Indeed, genomic studies have highlighted an upregulation of mRNA levels of the $\mathrm{CB}_{2} \mathrm{~A}$, but not the $\mathrm{CB}_{2} \mathrm{~B}$, isoform in the cerebellum of $\mathrm{BTBR} \mathrm{T}+\mathrm{tF} /$ $\mathrm{J}$ mice [105], which have an autism-like behavioral phenotype [106]. Also, an independent clinical study performed on young (3-9-year-old) children demonstrated that $\mathrm{CB}_{2}$ is highly expressed, both at transcriptional and translational levels, in peripheral blood mononuclear cells of patients with autism, compared with matched healthy controls [107]. All the other elements of the eCB system remained unaltered, except for a 
slight downregulation of NAPE-phospholipase D mRNA. According to a recent hypothesis on autism and inflammation [108], and in keeping with data on the key role of $\mathrm{CB}_{2}$ in immune-related pathologies [109-111], it can be speculated that the increase in $\mathrm{CB}_{2}$ expression may serve a compensatory role with respect to the inflammatory state associated with autism. Thus, the observed enhancement of $\mathrm{CB}_{2}$ may be a negative feedback response aimed at counteracting the proinflammatory responses implicated in the pathogenesis of this neurobehavioral condition. In this context, it should be also recalled that AEA suppresses the release of proinflammatory cytokines from human lymphocytes through a $\mathrm{CB}_{2}$-mediated mechanism [112]. The main alterations of the eCB system in human patients and animal models of autism are summarized in Tables 1 and 2, respectively. However, the paucity of the relevant human data and their largely correlational nature do not allow for a systematic comparison with the animal data.

Additionally, it is worth noting that plasma levels of polyunsaturated fatty acids (which are components of eCBs) are lower in patients with autism, and that 2 derivatives of docosahexaenoic acid and eicosapentaenoic acid (also components of eCBs) are able to activate both $\mathrm{CB}_{1}$ and $\mathrm{CB}_{2}$ receptors [113]. These data further suggest that a dysregulation of eCB signaling might be driven by diet, resulting in an imbalance of pro- and anti-inflammatory metabolites, and thus favoring the development of autism [114].

\section{Suggested Roles of the eCB System in Autism}

As discussed in the previous sections, there is phenotypic evidence across multiple levels that suggests a role for atypical reward system functioning in ASD. It is therefore vital to investigate in detail the eCB system in autism and related endophenotypes, also in view of its key role in modulating mesolimbic dopaminergic neurotransmission. The majority of studies on the eCB system in autism-related endophenotypes in humans have tested the role of the CNR1, which is strongly expressed in striatal structures implicated in processing

Table 1 Molecular markers of the endocannabinod (eCB) system in autism and related phenotypes in humans

\begin{tabular}{|c|c|c|c|}
\hline Biological sample & Model & $\mathrm{eCB}$ alterations & Reference \\
\hline Postmortem brain & Human & $\downarrow \mathrm{CB}_{1}$ & [121] \\
\hline PBMCs & Human & $\begin{array}{l}\downarrow N A P E-P L D \text { mRNA } \\
=\text { FAAH, CB }{ }_{1} \text { mRNA } \\
\uparrow \mathrm{CB}_{2} \text { mRNA and protein }\end{array}$ & [107] \\
\hline Saliva & Human & $\mathrm{CB}_{1} \mathrm{SNP}$ & {$[116,119]$} \\
\hline
\end{tabular}

PBMCs $=$ peripheral blood mononuclear cells; $\mathrm{CB}^{1}=$ type- 1 cannabinoid receptor; NAPE-PLD $=N$-acylphosphatidyl-ethanolamine-specific phospholipase $\mathrm{D}$; FAAH = fatty acid hydrolase; $\mathrm{CB} 2=$ type- 2 cannabinoid receptor; $\mathrm{SNP}=$ single nucleotide polymorphism rewards [115]. The previous section presented an overview of largely animal studies that point to a role for eCB signaling in autism-relevant phenotypes. Further clues from both human and animal studies are discussed in the following section, and are summarized in Fig. 3.

The first clue comes from a human neuroimaging study that measured striatal response to social rewards (happy faces $v s$ neutral faces). This investigation found that common single nucleotide polymorphisms in CNR1 are associated with activity in the ventral striatal cluster in response to happy (but not to disgusted) faces [116], and later on it was replicated in an independent cohort [117]. In view of the central role of the ventral striatum in reward processing, it is reasonable to infer that variation in $C N R 1$ was linked to differences in sensitivity to social rewards such as happy faces. Another study in an independent sample used eyegaze tracking to show that the same $C N R 1$ polymorphisms were associated with greater gaze duration to happy faces, but again not to disgust faces [118]. A parallel population genetic study found a nominal association of the same CNR1 genetic variations with trait empathy [119]. Individuals with ASD score low in trait empathy, and, consistent with this, a gene expression study in postmortem brains of individuals with autism had earlier reported a reduced expression of $\mathrm{CB}_{1}[120,121]$. In sum, multiple indirect lines of evidence suggest a role for $C N R 1$ genetic variations in underlying social reward responsivity, a putative endophenotype for autism. These findings in human patients parallel observations in animal models that show a strong role for the eCB system in social play behavior, which is a proxy measure for social reward responsivity $[122,123]$.

A second clue for the role of eCB system in autism comes from observations in early neural development [124]. Autism is neurodevelopmental in nature, and atypical development of neural connectivity has been suggested to underlie its key phenotypic features [125]. A set of genes involved in neurodevelopmental processes that mediate the formation, stabilization, and pruning of synapses has been consistently associated with autism-related phenotypes in animal models [126-128]. Neuroligins (NLGN) represent a significant part of this set, and indeed several genes of NLGN family have been associated with autism [129]. In a mouse model, an autism-associated mutation in NLGN3 was found to be associated with deficits in social behavior and disrupted tonic eCB signaling [130, 131]. Evidence from this study and several others (reviewed in [124]) provides a potential causal bridge between atypical neural development and potential dysfunction of the eCB system in autism.

A third clue comes from the role of the $\mathrm{eCB}$ system in influencing circadian rhythm in animal models [132-134]. Autism has been associated with atypical sleep patterns and circadian rhythms [135]. Polymorphisms in ASMT (involved in melatonin synthesis), paralleled by reduced levels of circulating melatonin, have been reported in autism [136]. 
Table 2 Molecular markers of the eCB system in autism-related animal models

\begin{tabular}{|c|c|c|c|}
\hline Biological sample & Model & eCBs alterations & Reference \\
\hline Striatum & fmrl $1^{-/}$mouse & $\begin{array}{l}=2-\mathrm{AG} \text { levels } \\
\uparrow \mathrm{DAGL} \text { and MAGL activity }\end{array}$ & {$[100]$} \\
\hline Cerebellum & Rat valproic acid & $\begin{array}{l}=\text { AEA, OEA, PEA and 2-AG levels } \\
\downarrow \text { DAGL } \alpha \text { mRNA }\end{array}$ & {$[104]$} \\
\hline Frontal cortex & & $\begin{array}{l}=\text { AEA, OEA, PEA and 2-AG levels } \\
\downarrow \text { PPAR- } \alpha \text { and } \downarrow \text { GPR } 55 \text { mRNA }\end{array}$ & \\
\hline Hippocampus & & $\begin{array}{l}\uparrow \mathrm{AEA}, \uparrow \mathrm{OEA}, \uparrow \mathrm{PEA} \text { content* } \\
\downarrow \mathrm{PPAR}-\gamma \text { and } \downarrow \text { GPR55 mRNA } \\
\downarrow \text { MAGL mRNA } \\
\uparrow \mathrm{MAGL} \text { activity }\end{array}$ & \\
\hline Cerebellum & $\mathrm{BTBR} \mathrm{T}+\mathrm{tF} / \mathrm{J}$ mouse & $\uparrow \mathrm{CB}_{2} \mathrm{~A}$ isoform mRNA & {$[105]$} \\
\hline
\end{tabular}

2-AG=2-arachidonoylglycerol; $\mathrm{DAGL}=$ diacylglycerol; $\mathrm{MAGL}=$ monacylglycerol lipase; $\mathrm{AEA}=$ anandamide; $\mathrm{OEA}=N$-oleoylethanolamine; $\mathrm{PEA}=N$-palmitoylethanolamine; $\mathrm{PPAR}=$ peroxisome proliferator-activated receptor

*After sociability tests

Interestingly, the eCB system also plays a role in regulating circadian rhythms [134], thus making it a putative target to examine using animal models of autism-related phenotypes.

The fourth clue comes from comorbidities commonly observed in autism. First of these is anxiety, which is highly comorbid with autism (42-56 \%). The eCB system, and cannabidiol in particular, is known to mediate anxiety and related phenotypes $[137,138]$. Anecdotal reports of cannabis use in autism suggest a reduction in anxiety-related symptoms. A potential role for the eCB system in ASD can thus also be mediated through its influence on the anxiety-related component of the disease. The second commonly occuring comorbidity in autism relevant to the current review is epilepsy (up to $30 \%$ ). The eCB system is studied intensively as targets for potential antiepileptic drugs [139]. It is therefore possible that a potential future drug acting on the $\mathrm{eCB}$ system is better able to ameliorate epilepsy-related comorbidities in ASD.

\section{Conclusions}

Accumulated evidence suggests that the eCB system constitutes a relatively less investigated piece of a puzzle that brings together 4 phenotypic features known to be atypical in autism: 1) social reward responsivity; 2) neural development; 3) circadian rhythm; and 4) anxiety-related symptoms. Therefore, the potential therapeutic exploitation of distinct elements of this system (e.g., receptor targets, biosynthetic and hydrolytic enzymes, and transmembrane/intracellular transporters)
Fig. 3 Four clues pointing to the role of the endocannabinoid (eCB) system in autism. The eCB system constitutes a relatively less investigated piece of a puzzle that brings together 4 phenotypic features known to be atypical in autism: 1) social reward responsivity; 2) neural development; 3) circadian rhythm; and 4) anxiety-related symptoms. $\mathrm{fMRI}=$ functional magnetic resonance imaging

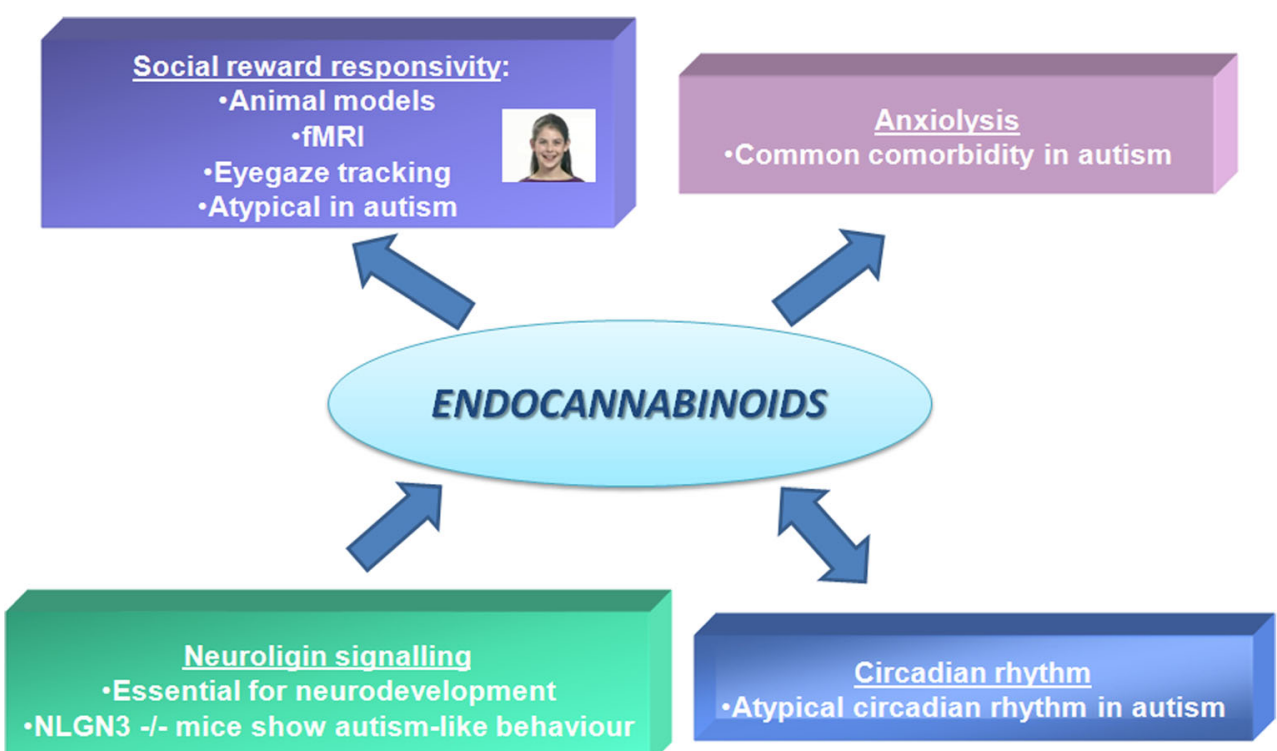


seems immense. As supported by the evidence presented in the previous sections in humans and animal models, any potential therapeutic approach is unlikely to involve a simple choice between activation versus inhibition of the eCB system to target specific features related to autism. Any such approach will need to be precisely tuned to the developmental timeline and to the specific pathogenetic underpinnings of autism in the single patient. Our understanding of eCB signaling in autism is still in its infancy compared with other disorders of the central nervous system or of peripheral tissues, where eCBbased therapies have already reached preclinical and clinical phases [4]. However, research in this field is rapidly evolving, and novel drugs able to hit specifically a distinct element of the eCB system are developed at a surprising speed [4]. Among them, those that target metabolic enzymes of eCBs, and, at the same time, key enzymes of oxidative pathways like cyclooxygenases seem to hold promise as next-generation therapeutics against human disorders with an inflammatory component [140], and therefore they will possibly result in also being beneficial for ASD. A second medium-term target could focus on the antiepileptic drugs that are being developed, focusing on the eCB system. These drugs could potentially ameliorate the epilepsy-related symptoms that commonly co-occur with ASD. On a final note, it seems of major interest that preliminary data, showing consistency between changes in distinct eCB system elements (i.e., $\mathrm{CB}_{2}$ ) in animal models of ASD and in peripherabl blood mononuclear cells from young patients with ASD [106, 107], support a role for these elements in the (early) diagnosis of the disease. Future work should test expression profiles for key players of the eCB system in prospective samples to test the potential of these as diagnostic biomarkers. In this context, it should be recalled that easily accessible biomarkers of neurological disorders are highly searched for, and some of them have been already identified to hold promise in human neurodegenerative/neuroinflammatory diseases [141].

Acknowledgments This investigation was partly supported by Ministero dell'Istruzione, dell'Università e della Ricerca (PRIN 20102011 grant) to MM. BC was supported by Medical Research Council UK (grant: G1100359/1).

Required Author Forms Disclosure forms provided by the authors are available with the online version of this article.

\section{References}

1. Matsuda LA, Lolait SJ, Brownstein MJ, Young AC, Bonner TI. Structure of a cannabinoid receptor and functional expression of the cloned cDNA. Nature 1990;346:561-564.

2. Pacher P, Kunos G. Modulating the endocannabinoid system in human health and disease-successes and failures. FEBS J 2013;280:1918-1943.
3. Maccarrone M, Guzman M, Mackie K, Doherty P, Harkany T. Programming and reprogramming neural cells by (endo-)cannabinoids: from physiological rules to emerging therapies. Nature Rev Neurosci 2014;15:786-801.

4. Maccarrone M, Bab I, Bíró T, et al. Endocannabinoid signaling at the periphery: 50 years after THC. Trends Pharmacol Sci 2015;36: 277-296.

5. Maccarrone M, Dainese E, Oddi S. Intracellular trafficking of anandamide: new concepts for signaling. Trends Biochem Sci 2010;35:601-608.

6. Ueda N, Tsuboi K, Uyama T. Metabolism of endocannabinoids and related N-acylethanolamines: canonical and alternative pathways. FEBS J 2013;280:1874-1894.

7. Fezza F, Bari M, Florio R, Talamonti E, Feole M, Maccarrone M. Endocannabinoids, related compounds and their metabolic routes. Molecules 2014;19:17078-17106.

8. Okamoto Y, Morishita J, Tsuboi K, Tonai T, Ueda N. Molecular characterization of a phospholipase $\mathrm{D}$ generating anandamide and its congeners. J Biol Chem 2004;279:5298-5305.

9. Cravatt BF, Giang DK, Mayfield SP, Boger DL, Lerner RA, Gilula NB. Molecular characterization of an enzyme that degrades neuromodulatory fatty-acid amides. Nature 1996;384:83-87.

10. Wei BQ, Mikkelsen TS, McKinney MK, Lander ES, Cravatt BF. A second fatty acid amide hydrolase with variable distribution among placental mammals. J Biol Chem 2006;281:36569-36578.

11. Tsuboi K, Sun YX, Okamoto Y, Araki N, Tonai T, Ueda N. Molecular characterization of $\mathrm{N}$-acylethanolamine-hydrolyzing acid amidase, a novel member of the choloylglycine hydrolase family with structural and functional similarity to acid ceramidase. J Biol Chem 2005;280:11082-11092.

12. Ueda N, Tsuboi K, Uyama T. $N$-acylethanolamine metabolism with special reference to $N$-acylethanolamine-hydrolyzing acid amidase (NAAA). Prog Lipid Res 2010;49:299-315.

13. Bisogno T, Howell F, Williams G, et al. Cloning of the first sn1DAG lipases points to the spatial and temporal regulation of endocannabinoid signaling in the brain. J Cell Biol 2003;163: 463-468.

14. Dinh TP, Freund TF, Piomelli D. A role for monoglyceride lipase in 2-arachidonoylglycerol inactivation. Chem Phys Lipids 2002;121:149-158.

15. Kozak KR, Crews BC, Morrow JD, et al. Metabolism of the endocannabinoids, 2-arachidonylglycerol and anandamide, into prostaglandin, thromboxane, and prostacyclin glycerol esters and ethanolamides. J Biol Chem 2002;277:44877-44885.

16. Kozak KR, Crews BC, Ray JL, Tai HH, Morrow JD, Marnett LJ. Metabolism of prostaglandin glycerol esters and prostaglandin ethanolamides in vitro and in vivo. J Biol Chem 2001;276: 36993-36998.

17. Van der Stelt M, van Kuik JA, Bari M, et al. Oxygenated metabolites of anandamide and 2-arachidonoylglycerol: conformational analysis and interaction with cannabinoid receptors, membrane transporter, and fatty acid amide hydrolase. J Med Chem 2002;45:3709-3720.

18. Chen JK, Chen J, Imig JD, et al. Identification of novel endogenous cytochrome $\mathrm{p} 450$ arachidonate metabolites with high affinity for cannabinoid receptors. J Biol Chem 2008;283:24514-24524.

19. Fowler CJ. Anandamide uptake explained? Trends Pharmacol Sci 2012;33:181-185.

20. Fowler CJ. Transport of endocannabinoids across the plasma membrane and within the cell. FEBS J 2013;280:18951904.

21. Ehehalt R, Füllekrug J, Pohl J, Ring A, Herrmann T, Stremmel W. Translocation of long chain fatty acids across the plasma membrane - lipid rafts and fatty acid transport proteins. Mol Cell Biochem 2006;284:135-140. 
22. Di Pasquale E, Chahinian H, Sanchez P, Fantini J. The insertion and transport of anandamide in synthetic lipid membranes are both cholesterol-dependent. PLoS One 2009;4:e4989.

23. Chicca A, Marazzi J, Nicolussi S, Gertsch J. Evidence for bidirectional endocannabinoid transport across cell membranes. J Biol Chem 2012;287:34660-34682.

24. Dainese E, Oddi S, Bari M, Maccarrone M. Modulation of the endocannabinoid system by lipid rafts. Curr Med Chem 2007;14:2702-2715.

25. Oddi S, Fezza F, Pasquariello N, et al. Evidence for the intracellular accumulation of anandamide in adiposomes. Cell Mol Life Sci 2008;65:840-850.

26. Maccarrone M, Bernardi G, Finazzi Agrò A, Centonze D. Cannabinoid receptor signalling in neurodegenerative diseases: a potential role for membrane fluidity disturbance. Br J Pharmacol 2011;163:1379-1390.

27. Di Marzo V, De Petrocellis L. Endocannabinoids as regulators of transient receptor potential (TRP) channels: a further opportunity to develop new endocannabinoid-based therapeutic drugs. Curr Med Chem 2010;17:1430-1449.

28. Zygmunt PM, Ermund A, Movahed P, et al. Monoacylglycerols activate TRPV1 $-\mathrm{a}$ link between phospholipase C and TRPV1. PLoS One 2013;8:e81618.

29. Pistis M, Melis M. From surface to nuclear receptors: the endocannabinoid family extends its assets. Curr Med Chem 2010;17:1450-1467.

30. Moriconi A, Cerbara I, Maccarrone M, Topai A. GPR55: current knowledge and future perspectives of a purported "type-3" cannabinoid receptor. Curr Med Chem 2010;17:1411-1429.

31. Ross RA. L- $\alpha$-lysophosphatidylinositol meets GPR55: a deadly relationship. Trends Pharmacol Sci 2011;32:265-269.

32. Di Marzo V, Stella N, Zimmer A. Endocannabinoid signalling and the deteriorating brain. Nat Rev Neurosci 2015;16:30-42.

33. Ben-Shabat S, Fride E, Sheskin T, et al. An entourage effect: inactive endogenous fatty acid glycerol esters enhance 2arachidonoyl-glycerol cannabinoid activity. Eur J Pharmacol 1998;353:23-31.

34. Costa B, Comelli F, Bettoni I, Colleoni M, Giagnoni G. The endogenous fatty acid amide, palmitoylethanolamide, has antiallodynic and anti-hyperalgesic effects in a murine model of neuropathic pain: involvement of CB(1), TRPV1 and PPARgamma receptors and neurotrophic factors. Pain 2008;139:541-550.

35. Ho WS, Barrett DA, Randall MD. "Entourage" effects of Npalmitoylethanolamine and $\mathrm{N}$-oleoylethanolamine on vasorelaxation to anandamide occur through TRPV1 receptors. Br J Pharmacol 2008;155:837-846.

36. American Psychiatric Association. Diagnostic and statistical manual of mental disorders. 5th ed. American Psychiatric Association, Arlington, VA, 2013.

37. Lord C, Rutter M, DiLavore PC, Risi S. ADOS, Autism Diagnostic Observation Schedule. Western Psychological Services, Los Angeles, CA, 2002.

38. Gotham K, Risi S, Pickles A, Lord C. The Autism Diagnostic Observation Schedule: revised algorithms for improved diagnostic validity. J Autism Dev Disord 2007;37:613-627.

39. Rutter M, Le Couter A, Lord C. ADI-R, Autism Diagnostic Interview-Revised. Western Psychological Services, Los Angeles, CA, 2003.

40. Persico AM. Autisms. In: Neural circuit development and function in the healthy and diseased brain: comprehensive developmental neuroscience, vol. 3 (Rakic P. and Rubenstein J, eds). Elsevier, New York, 2013, pp. 651-694.

41. Piven J, Palmer P, Jacobi D, Childress D, Arndt S. Broader autism phenotype: evidence from a family history study of multipleincidence autism families. Am J Psychiatry 1997;154:185-190.
42. Baron-Cohen S, Wheelwright S, Skinner R, Martin J, Clubley E. The autism-spectrum quotient (AQ): evidence from Asperger syndrome/high-functioning autism, males and females, scientists and mathematicians. J Autism Dev Disord 2001;31:5-17.

43. Developmental Disabilities Monitoring Network Surveillance Year 2010 Principal Investigators; Centers for Disease Control and Prevention (CDC). Prevalence of autism spectrum disorder among children aged 8 years - autism and developmental disabilities monitoring network, 11 sites, United States, 2010. MMWR Surveill Summ 2014;63:1-21.

44. Ozonoff S, Young GS, Carter A, et al. Recurrence risk for autism spectrum disorders: a Baby Siblings Research Consortium study. Pediatrics 2011;128:e488-e495.

45. Elsabbagh M, Fernandes J, Jane Webb S, et al. Disengagement of visual attention in infancy is associated with emerging autism in toddlerhood. Biol Psychiatry 2013;74:189-194.

46. Chawarska K, Shic F, Macari S, et al. 18-month predictors of later outcomes in younger siblings of children with autism spectrum disorder: a baby siblings research consortium study. J Am Acad Child Adolesc Psychiatry 2014;53:1317-1327.

47. Gangi DN, Ibañez LV, Messinger DS. Joint attention initiation with and without positive affect: risk group differences and associations with ASD symptoms. J Autism Dev Disord 2014;44: 1414-1424.

48. Gliga T, Jones EJ, Bedford R, Charman T, Johnson MH. From early markers to neuro-developmental mechanisms of autism. Dev Rev 2014;34:189-207.

49. Tuchman R, Rapin I. Epilepsy in autism. Lancet Neurol 2002;1: 352-358.

50. Fombonne E. Epidemiology of autistic disorder and other pervasive developmental disorders. J Clin Psychiatry 2005;66:3-8.

51. Souders MC, Mason TB, Valladares O, et al. Sleep behaviors and sleep quality in children with autism spectrum disorders. Sleep 2009;32:1566-1578.

52. Tarazi F, Sahli Z, Pleskow J, Mousa S. Asperger's syndrome: diagnosis, comorbidity and therapy. Expert Rev Neurother 2015;15:281-293.

53. Di Cicco-Bloom E, Lord C, Zwaigenbaum L, et al. The developmental neurobiology of autism spectrum disorder. J Neurosci 2006;26:6897-6906.

54. Amaral DG, Schumann CM, Nordahl CW. Neuroanatomy of autism. Trends Neurosci 2008; 31:137-145.

55. Blatt GJ. The neuropathology of autism. Scientifica 2012;2012: 703675.

56. Bauman ML, Kemper TL. Neuroanatomic observations of the brain in autism: a review and future directions. Int $\mathrm{J}$ Dev Neurosci 2005;23:183-187.

57. Rice D, Barone S Jr. Critical periods of vulnerability for the developing nervous system: evidence from humans and animal models. Environ Health Perspect 2000;108(Suppl. 3):511-533.

58. Geschwind DH, Levitt P. Autism spectrum disorders: developmental disconnection syndromes. Curr Opin Neurobiol 2007;17: 103-111.

59. Hahamy A, Behrmann M, Malach R. The idiosyncratic brain: distortion of spontaneous connectivity patterns in autism spectrum disorder. Nat Neurosci 2015;18:302-309.

60. Geschwind DH. Genetics of autism spectrum disorders. Trends Cogn Sci 2011;15:409-416.

61. Persico AM, Napolioni V. Autism genetics. Behav Brain Res 2013;251:95-112.

62. Persico AM, Merelli S. Environmental factors and autism spectrum disorder. Curr Dev Disord Rep 2014;1:8-19.

63. Tordjman S, Somogyi E, Coulon N, et al. Gene $\times$ environment interactions in autism spectrum disorders: role of epigenetic mechanisms. Front Psychiatry 2014;5:53. 
64. Vargas DL, Nascimbene C, Krishnan C, Zimmerman AW, Pardo CA. Neuroglial activation and neuroinflammation in the brain of patients with autism. Ann Neurol 2005;57:67-81.

65. Garbett KA, Ebert PJ, Mitchell A, et al. Immune transcriptome alterations in the temporal cortex of subjects with autism. Neurobiol Dis 2008;30:303-311.

66. Lintas C, Sacco R, Persico AM. Genome-wide expression studies in Autism spectrum disorder, Rett syndrome, and Down syndrome. Neurobiol Dis 2012;45:57-68.

67. Sacco R, Curatolo P, Manzi B, et al. Principal pathogenetic components and biological endophenotypes in autism spectrum disorders. Autism Res 2010;3:237-252.

68. Fox E, Amaral D, Van de Water J. Maternal and fetal antibrain antibodies in development and disease. Dev Neurobiol 2012;72: 1327-1334.

69. Onore C, Careaga M, Ashwood P. The role of immune dysfunction in the pathophysiology of autism. Brain Behav Immun 2012;26:383-392.

70. McElhanon BO, McCracken C, Karpen S, Sharp WG. Gastrointestinal symptoms in autism spectrum disorder: a metaanalysis. Pediatrics 2014;133:872-883.

71. Piras I, Haapanen L, Napolioni V, Sacco R, Van de Water J, Persico A. Anti-brain antibodies are associated with more severe cognitive and behavioural profiles in Italian children with Autism Spectrum Disorder. Brain Behav Immun 2014;38:91-99.

72. Chakrabarti B, Baron-Cohen S. Empathizing: neurocognitive developmental mechanisms and individual differences. Prog Brain Res 2006;156:403-417.

73. Chevallier C, Kohls G, Troiani V, Brodkin ES, Schultz RT. The social motivation theory of autism. Trends Cogn Sci 2012;16:231239.

74. Sims TB, Van Reekum CM, Johnstone T, Chakrabarti B. How reward modulates mimicry: EMG evidence of greater facial mimicry of more rewarding happy faces. Psychophysiology 2012;49: 998-1004.

75. Sims TB, Neufeld J, Johnstone T, Chakrabarti B. Autistic traits modulate frontostriatal connectivity during processing of rewarding faces. Soc Cogn Affect Neurosci 2014;9:2010201-2010206.

76. Dawson G, Carver L, Meltzoff AN, Panagiotides H, McPartland J, Webb SJ.Neural correlates of face and object recognition in young children with autism spectrum disorder, developmental delay, and typical development. Child Dev 2002;73:700-717.

77. Pierce K, Conant D, Hazin R, Stoner R, Desmond J. Preference for geometric patterns early in life as a risk factor for autism. Arch Gen Psychiatry 2011;68:101-109.

78. Schmitz N, Rubia K, van Amelsvoort T, Daly E, Smith A, Murphy DG. Neural correlates of reward in autism. Br J Psychiatry 2008;192:19-24.

79. Dichter GS, Richey JA, Rittenberg AM, Sabatino A, Bodfish JW. Reward circuitry function in autism during face anticipation and outcomes. J Autism Dev Disord 2012;42:147-160.

80. Kohls G, Schulte-Rüther M, Nehrkorn B, Reward system dysfunction in autism spectrum disorders. Soc Cogn Affect Neurosci 2013;8:565-572.

81. Demurie E, Roeyers H, Baeyens D, Sonuga-Barke E. Common alterations in sensitivity to type but not amount of reward in ADHD and autism spectrum disorders. J Child Psychol Psychiatry 2011;52:1164-1173.

82. Dawson G, Bernier R, Ring RH. Social attention: a possible early indicator of efficacy in autism clinical trials. J Neurodev Disord 2012;4:11.

83. Fletcher-Watson S, Leekam SR, Benson V, Frank MC, Findlay JM. Eye-movements reveal attention to social information in autism spectrum disorder. Neuropsychologia 2009;47:248-257.

84. Klin A, Jones W, Schultz R, Volkmar F, Cohen D. Visual fixation patterns during viewing of naturalistic social situations as predictors of social competence in individuals with autism. Arch Gen Psychiatry 2002;59:809-816.

85. Sasson NJ, Dichter GS, Bodfish JW. Affective responses by adults with autism are reduced to social images but elevated to images related to circumscribed interests. PLoS One 2012;7:e42457.

86. Krajbich I, Armel C, Rangel A. Visual fixations and the computation and comparison of value in simple choice. Nat Neurosci 2010;13:1292-1298.

87. Stavropoulos KK, Carver LJ. Effect of familiarity on reward anticipation in children with and without autism spectrum disorders. PLoS One 2014;9:e106667.

88. Richey JA, Rittenberg A, Hughes L, et al. Common and distinct neural features of social and non-social reward processing in autism and social anxiety disorder. Soc Cogn Affect Neurosci 2014;9:367-377.

89. Chakrabarti B, Bullmore E, Baron-Cohen S. Empathizing with basic emotions: common and discrete neural substrates. Soc Neurosci 2006;1:364-384.

90. Ruggeri B, Sarkans U, Schumann G, Persico AM. Biomarkers in autism spectrum disorder: the old and the new. Psychopharmacology 2014;231:1201-1216.

91. Vorstman JA, Spooren W, Persico AM, et al. Using genetic findings in autism for the development of new pharmaceutical compounds. Psychopharmacology 2014;231:1063-1078.

92. Battista N, Bari M, Tarditi A, et al. Severe deficiency of the fatty acid amide hydrolase (FAAH) activity segregates with the Huntington's disease mutation in peripheral lymphocytes. Neurobiol Dis 2007;27:108-116.

93. Centonze D, Battistini L, Maccarrone M. The endocannabinoid system in peripheral lymphocytes as a mirror of neuroinflammatory diseases. Curr Pharm Des 2008;14:23702382.

94. Marco EM, Scattoni ML, Rapino C, et al. Emotional, endocrine and brain anandamide response to social challenge in infant male rats. Psychoneuroendocrinology 2013;38:2152-2162.

95. Sciolino NR, Bortolato M, Eisenstein SA, et al. Social isolation and chronic handling alter endocannabinoid signaling and behavioral reactivity to context in adult rats. Neuroscience 2010;168: 371-386.

96. Marco EM, Rapino C, Caprioli A, Borsini F, Maccarrone M, Laviola G. Social encounter with a novel partner in adolescent rats: activation of the central endocannabinoid system. Behav Brain Res 2011;220:140-145.

97. Bagni C, Tassone F, Neri G, Hagerman R. Fragile X syndrome: causes, diagnosis, mechanisms, and therapeutics. J Clin Invest 2012;122:4314-4322.

98. Ludwig AL, Espinal GM, Pretto DI, et al. CNS expression of murine fragile $\mathrm{X}$ protein (FMRP) as a function of CGG-repeat size. Hum Mol Genet 2014;23:3228-3238.

99. Gürkan CK, Hagerman RJ. Targeted treatments in autism and Fragile X syndrome. Res Autism Spectr Disord 2012;6:13111320 .

100. Maccarrone M, Rossi S, Bari M, et al. Abnormal mGlu 5 receptor/ endocannabinoid coupling in mice lacking FMRP and BC1 RNA. Neuropsychopharmacology. 2010;35:1500-1509.

101. Jung KM, Sepers M, Henstridge CM, et al. Uncoupling of the endocannabinoid signalling complex in a mouse model of fragile X syndrome. Nat Commun 2012;3:1080

102. Busquets-Garcia A, Gomis-González M, Guegan T, et al. Targeting the endocannabinoid system in the treatment of fragile X syndrome. Nat Med 2013;19:603-607.

103. Schultz ST. Can autism be triggered by acetaminophen activation of the endocannabinoid system? Acta Neurobiol Exp (Wars) 2010;70:227-231. 
104. Kerr DM, Downey L, Conboy M, Finn DP, Roche M. Alterations in the endocannabinoid system in the rat valproic acid model of autism. Behav Brain Res 2013;249:124-132.

105. Liu QR, Pan CH, Hishimoto A, et al. Species differences in cannabinoid receptor 2 (CNR2 gene): identification of novel human and rodent $\mathrm{CB} 2$ isoforms, differential tissue expression and regulation by cannabinoid receptor ligands. Genes Brain Behav 2009;8:519-530.

106. Onaivi ES, Benno R, Halpern T, et al. Consequences of cannabinoid and monoaminergic system disruption in a mouse model of autism spectrum disorders. Curr Neuropharmacol 2011;9:209214.

107. Siniscalco D, Sapone A, Giordano C, et al. Cannabinoid receptor type 2, but not type 1, is up-regulated in peripheral blood mononuclear cells of children affected by autistic disorders. J Autism Dev Disord 2013;43:2686-2695.

108. Depino AM. Peripheral and central inflammation in autism spectrum disorders. Mol Cell Neurosci 2013;53:69-76.

109. Leleu-Chavain N, Desreumaux P, Chavatte P, Millet R. Therapeutical potential of $\mathrm{CB}_{2}$ receptors in immune-related diseases. Curr Mol Pharmacol 2013;6:183-203.

110. Rom S, Persidsky Y. Cannabinoid receptor 2: potential role in immunomodulation and neuroinflammation. J Neuroimmune Pharmacol 2013;8:608-620.

111. Chiurchiù V, Battistini L, Maccarrone M. Endocannabinoid signaling in innate and adaptive immunity. Immunol 2015;144:352364.

112. Cencioni MT, Chiurchiù V, Catanzaro G, et al. Anandamide suppresses proliferation and cytokine release from primary human Tlymphocytes mainly via CB2 receptors. PLoS One 2010;5:e8688.

113. Brown I, Cascio MG, Rotondo D, Pertwee RG, Heys SD, Wahle KW. Cannabinoids and omega-3/6 endocannabinoids as cell death and anticancer modulators. Prog Lipid Res 2013;52:80-109.

114. Das U. Autism as a disorder of deficiency of brain-derived neurotrophic factor and altered metabolism of polyunsaturated fatty acids. Nutrition 2013;29:1175-1185.

115. Van der Stelt M, Di Marzo V. The endocannabinoid system in the basal ganglia and in the mesolimbic reward system: implications for neurological and psychiatric disorders. Eur J Pharmacol 2003;480:133-150.

116. Chakrabarti B, Kent L, Suckling J, Bullmore E, Baron-Cohen S. Variations in the human cannabinoid receptor (CNR1) gene modulate striatal responses to happy faces. Eur J Neurosci 2006;23: 1944-1948.

117. Domschke K, Dannlowski U, Ohrmann P, et al. Cannabinoid receptor 1 (CNR1) gene: impact on antidepressant treatment response and emotion processing in major depression. Eur Neuropsychopharmacol 2008;18:751-759.

118. Chakrabarti B, Baron-Cohen S. Variation in the human cannabinoid receptor CNR1 gene modulates gaze duration for happy faces. Mol Autism 2011;2:10.

119. Chakrabarti B, Dudbridge F, Kent L, et al. Genes related to sex steroids, neural growth, and social-emotional behavior are associated with autistic traits, empathy, and Asperger syndrome. Autism Res 2009;2:157-177.

120. Baron-Cohen S, Wheelwright $\mathrm{S}$. The empathy quotient: an investigation of adults with Asperger syndrome or high functioning autism, and normal sex differences. J Autism Dev Disord 2004;34:163-175.

121. Purcell AE, Jeon OH, Zimmerman AW, Blue ME, Pevsner J. Postmortem brain abnormalities of the glutamate neurotransmitter system in autism. Neurol 2001;57:1618-1628.
122. Trezza V, Vanderschuren LJ. Bidirectional cannabinoid modulation of social behavior in adolescent rats. Psychopharmacol 2008;197:217-227.

123. Trezza V, Baarendse PJ, Vanderschuren LJ. The pleasures of play: pharmacological insights into social reward mechanisms. Trends Pharmacol Sci 2010;31:463-469.

124. Maccarrone M, Guzmán M, Mackie K, Doherty P, Harkany T. Programming of neural cells by (endo)cannabinoids: from physiological rules to emerging therapies. Nat Rev Neurosci 2014;15: 786-801.

125. Belmonte MK, Allen G, Beckel-Mitchener A, Boulanger LM, Carper RA, Webb SJ. Autism and abnormal development of brain connectivity. J Neurosci 2004;24:9228-9231.

126. Persico AM, Bourgeron T. Searching for ways out of the autism maze: genetic, epigenetic and environmental clues. Trends Neurosci 2006;29:349-358.

127. Spooren W, Lindemann L, Ghosh A, Santarelli L. Synapse dysfunction in autism: a molecular medicine approach to drug discovery in neurodevelopmental disorders. Trends Pharmacol Sci 2012;33:669-684.

128. Tsai NP, Wilkerson JR, Guo W, et al. Multiple autism-linked genes mediate synapse elimination via proteasomal degradation of a synaptic scaffold PSD-95. Cell 2012;151:1581-1594.

129. Bourgeron T. A synaptic trek to autism. Current Opin Neurobiol 2009;19:231-234.

130. Jaramillo TC, Liu S, Pettersen A, Birnbaum SG, Powell CM. Autism-related neuroligin-3 mutation alters social behavior and spatial learning. Autism Res 2014;7:264-272.

131. Földy C, Malenka RC, Südhof TC. Autism-associated neuroligin3 mutations commonly disrupt tonic endocannabinoid signaling. Neuron 2013;78:498-509.

132. Cota D, Steiner MA, Marsicano G, et al. Requirement of cannabinoid receptor type 1 for the basal modulation of hypothalamicpituitary-adrenal axis function. Endocrinol 2007;148:1574-1581.

133. Atkinson HC, Leggett JD, Wood SA, Castrique ES, Kershaw YM, Lightman SL. Regulation of the hypothalamic-pituitary-adrenal axis circadian rhythm by endocannabinoids is sexually diergic. Endocrinol 2010;15:3720-3727.

134. Vaughn LK, Denning G, Stuhr KL, de Wit H, Hill MN, Hillard CJ. Endocannabinoid signalling: has it got rhythm? Br J Pharmacol 2010;160:530-543.

135. Glickman G. Circadian rhythms and sleep in children with autism. Neurosci Biobehav Rev 2010;34:755-768.

136. Melke J, Goubran Botros H, Chaste P. Abnormal melatonin synthesis in autism spectrum disorders. Mol Psychiat 2008;13:90-98.

137. Campos AC, Guimarães FS.Involvement of 5HT1A receptors in the anxiolytic-like effects of cannabidiol injected into the dorsolateral periaqueductal gray of rats. Psychopharmacology 2008;199:223-230.

138. Rubino T, Guidali C, Vigano D, et al. CB1 receptor stimulation in specific brain areas differently modulate anxiety-related behaviour. Neuropharmacol 2008;54:151-160.

139. Katona I, Freund TF. Endocannabinoid signaling as a synaptic circuit breaker in neurological disease. Nat Med 2008;14:923-930.

140. Sasso O, Migliore M, Habrant D, et al. Multitarget fatty acid amide hydrolase/cyclooxygenase blockade suppresses intestinal inflammation and protects against nonsteroidal anti-inflammatory drug dependent gastrointestinal damage. FASEB J 2015;29:2616-2627.

141. Arosio B, D'Addario C, Gussago C, et al. Peripheral blood mononuclear cells (PBMCs) as a laboratory to study dementia in the elderly. BioMed Res Int 2014;2014:169203. 